\title{
Determinants of better health: a cross-sectional assessment of positive deviants among women in West Bengal
}

\author{
Katelyn NG Long ${ }^{1 *}$, Lisa H Gren ${ }^{1}$, Chris A Rees ${ }^{1}$, Joshua H West ${ }^{2}$, Parley Cougar Hall², Bobbi Gray ${ }^{3}$ and \\ Benjamin T Crookston ${ }^{2}$
}

\begin{abstract}
Background: Rural women in West Bengal have been found to have low rates of formal education, poor health knowledge, high rates of malnutrition and anemia, and low levels of empowerment. Despite these difficult circumstances, some women have positive health outcomes compared to women with similarly disadvantaged backgrounds. The purpose of this study is to identify factors associated with positive health outcomes among women with primary education or less.

Methods: Multivariable regression models were built for outcomes of positive deviance to better characterize the factors in a woman's life that most impact her ability to deviate from the status quo.

Results: Positive deviants in this context are shown to be women who are able to earn an income, who have access to information through media sources, and who, despite little schooling, have marginally higher levels of formal education that lead to improved health outcomes.

Conclusions: Study findings indicate that positive deviant women in disadvantaged circumstances can achieve positive outcomes amidst a host of contextual barriers that would predict poor health outcomes. Focusing on areas such as enhancing access to media sources, facilitating self-help groups for married women, and promoting prolonged education and delayed marriage for girls may improve health knowledge and behavior among married women with low levels of education.
\end{abstract}

Keywords: India, Women, West Bengal, Positive deviance, Health, Education

\section{Background}

Women in West Bengal, India have been shown to have inadequate knowledge regarding HIV/AIDS [1], female reproductive issues [2], and communicable disease [3]. Research focused on mothers in West Bengal has shown low rates of oral contraceptive use [4,5], high rates of unwanted sexual encounters [6], and high rates of cervical cancer [7]. Moreover, women in West Bengal experience food insecurity [8], which has been associated with malnutrition $[9,10]$ and anemia [11]. Low education [12], poverty and lack of empowerment [13], all of which are common in West Bengal, are among the most common risk factors for

\footnotetext{
* Correspondence: katelyn.noel.long@gmail.com

'Department of Family and Preventive Medicine, University of Utah, Salt Lake City, UT, USA

Full list of author information is available at the end of the article
}

poor health behaviors. These challenges facing mothers in West Bengal have given rise to programs designed to reduce negative impacts, and include microfinance groups, education groups, and self-help groups (SHGs). Microfinance groups (including credit, savings, insurance and other financial services for the poor) have been shown to decrease poverty and health access inequities [14], increase the ability of members to seek formal health care [15], lead to improved nutritional status among participants [16], and improve social status through further work opportunities $[17,18]$. SHGs have been shown to decrease emotional stress [19], reduce infant mortality rates through preventive education [20], and increase HIV/ AIDS knowledge [21]. Despite these favorable outcomes, SHGs and microfinance groups have been criticized for

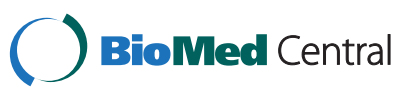


cultural insensitivity [22] and a failure to improve some basic health practices, such as contraceptive use [23].

Positive deviance is a phenomenon often found in resource-poor communities "where a few individuals and families employ uncommon, beneficial practices that allow them and their children to have better health as compared to their similarly impoverished neighbors" [24]. Positive deviance is founded on the idea that the most appropriate solutions to challenges are not found externally, but rather already exist within a given population [24]. This relies upon a community's existing resources and strengths to achieve sustainable and culturally appropriate improvements to health. Positive deviance involves identifying unique individuals, or positive deviants, within a community who engage in uncommon practices enabling them to achieve better results than others in their community with similar resources. Once identified, positive deviants can share solutions to mutual challenges with other community members. Programs focused on identifying, understanding, and utilizing positive deviants have been shown to improve nutritional status [25,26], obesity [27], pregnancy outcomes [28], HIV/AIDS prevention behavior [29], psychosocial outcomes such as more responsive parenting, and breastfeeding [30].

The purpose of this study was to examine behaviors and attitudes exhibited by positive deviants among a sample of women in West Bengal who are married, have children, are involved in a SHG, and have little or no formal education. Specifically, this study sought to identify factors associated with positive health outcomes among women with primary education or less. Identifying these factors can assist a variety of organizations in selecting strategies to improve health knowledge, behaviors, and outcomes more appropriately among disadvantaged populations.

\section{Methods \\ Population}

Data for this study came from a community-based, cluster-randomized controlled trial conducted in a rural population in the Nadia district of West Bengal, India from 2006 to 2009 [31,32]. The study was carried out by Freedom from Hunger, an international organization that focuses on integrated microfinance, health education and social services, and Reach India, a social enterprise that provides training to local organizations that facilitates womens' self-help groups (SHGs). Reach India trained a local NGO, Sri Mayapur Vikas Sangha (SMVS), to provide non-formal education on health and finance to women and their adolescent daughters and daughters-in-law through the SHGs. Surveys were completed for a total of 2227 consenting women and adolescent girls. An additional 81 potential respondents were approached, but declined to participate resulting in an overall response rate of $96.5 \%$. Of the 2227 women and girls who completed surveys, 537 were married, had children, were members of a SHG, and had primary education or less. These 537 women comprised the study population for our investigation of positive deviants.

\section{Measurement}

Five outcomes of importance to women in resourcepoor settings were identified and analyzed to see which factors may have affected a woman's ability to make healthier, more informed choices despite having low levels of education. The five outcomes were: 1 ) belief in a later age for marriage; 2) belief that a girl should stay in school longer; 3) awareness of HIV/AIDS; 4) correct knowledge of menstruation; and 5) perceived ability to travel alone to another village for health services. Each of these outcomes has been well established in the literature as a protective factor for women in resource-poor settings. Early marriage for girls and women is a predictor for a myriad of undesirable health and social outcomes including increased poverty, gender inequality, decreased education, HIV infection, cervical cancer, and child mortality [33-37]. Likewise, access to education is widely considered both a structural and social determinant of health that holds great promise for women in resource-poor settings [35]. Increasing women's awareness of HIV/AIDS is one of several key objectives in preventing this epidemic and has been a United Nations' Millennium Development Goal indicator for combating HIV/AIDS [38]. There remains much to do to achieve this goal, as up to $40 \%$ of some female populations in India have never heard of HIV/AIDS $[39,40]$. Women who lack knowledge about menstruation are vulnerable to a variety of sexual health challenges including reproductive tract infections and psycho-social stress related to menarche [41-43]. Finally, perceived ability to travel alone to another village for health services is a measure of empowerment that has been identified as key to womens' health [44].

A number of variables in the original dataset were combined to create composite variables for this analysis. A food security score was created using questions from a modified version of the US Household Food Security Scale Module (US HFFSM) [45-47]. Several questions on health knowledge were included in the questionnaire. We used correct responses to "The time during the month when a female loses blood happens because__??", "Have you heard about HIV/AIDS?", and "If a child has diarrhea, would you give him or her 'more,' 'less', 'the same', or 'nothing, to drink?" to create a variable that indicated 0 through 3 correct answers. For analyses where having the correct answer was the outcome of interest, we removed that question from the composite and modeled health knowledge on 0 to 2 correct answers for the remaining questions. We created a variable "earnings" that included money received as a gift as well as money earned, which 
was subsequently put into savings. This variable was analyzed in quartiles.

\section{Ethical considerations}

RTI International's Committee for the Protection of Human Subjects approved this study. There were no adverse events either observed or reported during this study.

\section{Survey development}

Several existing survey instruments were adapted for use in this study, including the Demographic and Health Survey (DHS) and a youth survey developed by the International Center for Research on Women (ICRW) for their Development Initiative on Supporting Healthy Adolescents (DISHA) program [31]. Questions included information on demographics (age, education, religion, household composition, food security and socio-economic indicators), general health behavior and knowledge indicators (HIV, diarrhea, disease prevention, etc.), and indicators of empowerment.

\section{Survey administration}

Freedom from Hunger, Reach India, and the Centre for Micro Finance trained a team of local female investigators to administer the surveys. Prior to implementation, the survey was pilot tested and female interviewers were trained on specific strategies for interviewing women and their adolescent daughters and daughters-in-law. Data used in this analysis were collected in May and June of 2008, prior to the rollout of the nonformal health and financial education.

\section{Data analysis}

Data were double entered, with any discrepancies being reconciled with hard copies of survey questionnaires. Statistical analyses were conducted using Stata ${ }^{\circledR}$ statistical software (version 11.1, College Station, TX, USA). Multivariable regression models were built for each of the five outcomes of positive deviance to better characterize the factors in a woman's life that most impacted her ability to deviate from the status quo. Core linear models were built for continuous outcomes for age in years for 1) belief in a later age for a girl to get married, and 2) belief in a later age for a girl to complete her studies. We also examined a logistic model evaluating belief in later marriage age ( $>=18$ years relative to $<18$ years). Core logistic models were built for 3) awareness of HIV/AIDS, 4) understanding the reason for menstruation, and 5) empowerment (traveling to another village for health services) (Table 1). All multivariable regression analyses adjusted for age, highest grade completed, and food security. Three of the models (belief in a later age for a girl to get married; HIV/AIDS awareness; and correct understanding of menstruation) were also adjusted for religion due to its significant role in improving the model's explanatory power. Several independent variables were identified by the investigators as potential predictors of positive deviance including number of pregnancies; age at first pregnancy; hand washing behavior; who women talked to about health and reproductive issues; number of rooms in their dwelling; and items within their household like television, radios, and cameras. These variables were added individually to the linear and logistic models and were analyzed for significance within the model $(\mathrm{p}<0.05)$ and significant improvement of the models' explanatory power (increase of Pseudo $\mathrm{R}^{2}$ or Adjusted $\mathrm{R}^{2}$ ). Regression diagnostics were run for all models including tests for normality of continuous variables and multicollinearity among independent variables.

\section{Results}

Demographic characteristics for the participants are provided in Table 2. Results from the linear regression model predicting belief in a later age for a girl to finish her studies are provided in Table 3. A one-year increase in ideal age of marriage predicted a 0.3-year increase in the ideal age for a girl to finish her studies $(\beta=0.301, p<0.001$, [95\% CI: $0.15,0.45])$. Women that reported greater health knowledge also thought the ideal age to finish school was nearly 1 year older compared to women who responded incorrectly to a series of health related questions $(\beta=0.871$, $\mathrm{p}<0.05$, [95\% CI: 0.23, 1.51]). A similar logistic model examining belief in a later age for a girl to get married found that compared to women who felt that a girl should finish her studies at a younger age (before age 18), women who believed in an older age for finishing studies had 3.8 times higher odds of thinking that the ideal age for marriage was age 18 or older ( $\mathrm{p}=0.001,[95 \% \mathrm{CI}: 1.68,8.68])$ (Data table not included).

Logistic regression modeling awareness of HIV/AIDS (Table 4) demonstrated that women who correctly answered questions about menstruation and diarrhea treatment had 2.7 times the odds of knowing about HIV/AIDS compared to women who answered neither question correctly ( $\mathrm{p}<0.05$, [95\%CI: $1.29,5.46])$. Women who reported receiving health information from the television or radio had 7.7 times the odds of knowing about HIV/AIDS than women who only received health information from friends and family ( $\mathrm{p}<0.001,[95 \% \mathrm{CI}: 4.38,13.60])$. In order to avoid over-fitting the model, other independent variables of interest were evaluated in separate models comprised of the HIV/AIDS core model variables plus one additional independent variable. These models are presented in Table 5.

The logistic regression model for a woman's perceived ability to travel alone to another village for health services (Table 6) indicated that women who had earned money in the last six months had 2.5 times the odds of being able to 
Table 1 Characteristics of outcome variables in the 5 core models

\begin{tabular}{|c|c|c|c|c|}
\hline Outcome variable (Linear) & Answer scale & Mean (sd) & Median & Range \\
\hline What is the ideal age for a girl to get married? & Single year of age & $18.71(1.53)$ & 18 & $10-26$ \\
\hline What is the ideal age a girl should finish her studies? & Single year of age & $18.55(2.70)$ & 18 & $10-30$ \\
\hline Outcome variable (Logistic) & Answer scale & & n (\%) & \\
\hline \multirow[t]{2}{*}{ Have you heard about HIV/AIDS? } & Yes & & $146(27.19)$ & \\
\hline & No & & $391(72.81)$ & \\
\hline \multirow{7}{*}{$\begin{array}{l}\text { The time during the month when a female loses } \\
\text { blood happens because? }\end{array}$} & Correct: & & & \\
\hline & An egg has not united with a male sperm & & $166(30.91)$ & \\
\hline & Incorrect: & & & \\
\hline & A woman is not eating enough & & $8(1.49)$ & \\
\hline & A woman is not clean & & $22(4.10)$ & \\
\hline & Do not know & & $330(61.45)$ & \\
\hline & Other & & $11(2.05)$ & \\
\hline \multirow{2}{*}{$\begin{array}{l}\text { Can you go to a health service in a nearby village } \\
\text { unescorted or alone? }\end{array}$} & Yes & & $334(62.20)$ & \\
\hline & No & & $203(37.80)$ & \\
\hline
\end{tabular}

travel alone when compared to women who had not earned money in the last six months $(\mathrm{p}<0.001$, [95\%CI: $1.73,3.68]$ ). Further, the odds of being able to travel alone to another village were twice as high for older women compared to women under age 25 , and nearly twice as high for women with some schooling compared to those with no schooling. Additionally, women who met the definition for food insecurity had nearly twice the odds of being able to travel for health services compared to women who were food secure ( $\mathrm{p}<0.05$, [95\%CI: 1.20, 2.55]). Our final logistic model was created to predict correct

Table 2 Demographic characteristics of 537 women meeting study criteria ${ }^{\text {a }}$

\begin{tabular}{|c|c|c|c|c|}
\hline & Mean (sd) & Median & Range & $\%$ Yes \\
\hline Age (years) & $32.42(8.97)$ & 31 & $16-63$ & \\
\hline Attended school & & & & 47.86 \\
\hline Highest grade passed & $3.82(1.50)$ & 4 & $1-6$ & \\
\hline Age at marriage & $15.65(2.26)$ & 15 & $10-30$ & \\
\hline Age at first pregnancy & $17.33(2.65)$ & 17 & $12-32$ & \\
\hline Number of times pregnant & $3.12(1.49)$ & 3 & $1-11$ & \\
\hline Number of children & $2.66(1.19)$ & 2 & $1-8$ & \\
\hline $\begin{array}{l}\text { Earned money in the } \\
\text { last } 6 \text { mo. }\end{array}$ & & & & 45.23 \\
\hline Rupees Earned in last month & $183.90(357.74)$ & 0.00 & $0-3000$ & \\
\hline Food Secure & & & & 53.45 \\
\hline Number of rooms in dwelling & $1.76(0.85)$ & 2 & $0-7$ & \\
\hline \multicolumn{5}{|l|}{ Religion } \\
\hline Hindu & & & & 49.35 \\
\hline Muslim & & & & 50.65 \\
\hline
\end{tabular}

a Study criteria: married, having one or more children, and having primary education or less. knowledge of menstruation (data not shown). After controlling for age, highest grade completed, and food security, women who had heard of HIV/AIDS had 2.4 times the odds of knowing the correct reason for menstruation when compared to women who had not heard of HIV/ AIDS ( $<<0.001$, [95\%CI: 1.54, 3.60]).

\section{Discussion}

This study sought to detect characteristics of positive deviance that occur in the lives of women with low educational attainment, for the purpose of determining whether the sources that influence positive behavior can be enhanced or replicated by groups and organizations that work with women in this region. Using this perspective, our research demonstrates that even modest improvements in formal educational level completed were associated with key outcomes. Further, our results indicate that women earning and saving money expressed higher levels of empowerment, and that women were more likely to receive health education messages related to HIV through media such as television and radio than through friends. These findings are critical in helping practitioners identify focus areas among married women with little or no education where gains might be made to improve health outcomes.

\section{Delaying marriage and increasing education}

Similar to our results, others have demonstrated that age of marriage and educational attainment in girls are associated [48]. Delaying marriage provides girls with the opportunity to pursue further studies. And as our study findings suggest, even modest improvements in formal education have a meaningful impact on women's health knowledge and behavior. For example, studies have found that formal education is directly correlated with better awareness of 
Table $\mathbf{3}$ Linear regression model for ideal age for a girl to finish her studies

\begin{tabular}{|c|c|c|c|c|c|c|}
\hline \multirow[t]{2}{*}{ Independent variables } & \multicolumn{3}{|c|}{ Unadjusted } & \multicolumn{3}{|c|}{ Adjusted } \\
\hline & $\beta$ Coefficient & $\mathrm{Cl} 95 \%$ & $P$-value & $\beta$ Coefficient & $\mathrm{Cl} 95 \%$ & $P$-value \\
\hline $\mathrm{Age}^{\mathrm{a}}$ & 0.01 & $-0.02,0.04$ & 0.387 & 0.02 & $-0.002,0.05$ & 0.066 \\
\hline Highest grade completed $^{\mathrm{b}}$ & 0.19 & $0.09,0.29$ & $<0.001$ & 0.17 & $0.06,0.28$ & 0.002 \\
\hline Food Security (ref: food secure) & 0.03 & $-0.44,0.49$ & 0.905 & 0.11 & $-0.34,0.57$ & 0.632 \\
\hline Ideal age for a girl to get Married ${ }^{c}$ & 0.32 & $0.17,0.47$ & $<0.001$ & 0.30 & $0.15,0.45$ & $<0.001$ \\
\hline \multicolumn{7}{|c|}{ Health Knowledge (ref: 0 correct responses) } \\
\hline 1 correct response & -0.02 & $-0.57,0.53$ & 0.949 & -0.19 & $-0.74,0.36$ & 0.496 \\
\hline $2-3$ correct responses & 1.19 & $0.56,1.81$ & $<0.001$ & 0.87 & $0.23,1.51$ & 0.008 \\
\hline
\end{tabular}

Model included 524 respondents; $r^{2}=8.68 \%$; constant $=11.62$ years.

age: 16-63 years old.

bhighest grade finished: $0-6$.

cideal age for a girl to get married: $10-26$ years old

'Health Knowledge scale composed of 3 questions: "Have you ever heard of HIV/AIDS?", "The time during the month when a female loses blood happens

because__?", "If a child has diarrhea, would you give him or her 'more', 'less', 'the same', or 'nothing', to drink?".

HIV/AIDS and reproductive care $[1,21,49,50]$, and have also explored why education, even in small amounts, seems to make a positive impact on health knowledge like HIV/AIDS. Interestingly, in West Bengal, where AIDS awareness is fairly low, the effect of formal education on the odds that an ever-married woman is aware of AIDS has been shown to be greater than the effect of formal education in other Indian states where HIV is thought to be highly prevalent [1]. In this study, compared to women with no formal education, women who had completed class 1-3 were more likely to have heard of HIV/AIDS and be knowledgeable about menstruation, and women who had completed class 4-6 were even more knowledgeable about HIV/AIDS and menstruation.
While the difference between completing classes 1-3 and classes 4-6 might not seem very large and the exact modality of how formal education improves outcomes is not completely understood, these examples demonstrate that small gains in formal education do make a considerable impact on health knowledge and empowerment in adult life. Providing access to primary and secondary education for children has been a continued priority for India [51]. However, for women who are already beyond the age of formal education, this study provides encouraging data for those willing to invest in education. Women with more than 1 year of participation in a SHG had higher odds of correct knowledge of HIV/AIDS compared to women with less than 1 year of participation. Furthermore, increased

Table 4 Logistic regression model for knowledge of HIV/AIDS

\begin{tabular}{|c|c|c|c|c|c|c|}
\hline \multirow[t]{2}{*}{ Independent variables } & \multicolumn{3}{|c|}{ Unadjusted } & \multicolumn{3}{|c|}{ Adjusted } \\
\hline & OR & $\mathrm{Cl} 95 \%$ & $P$-value & OR & $\mathrm{Cl} 95 \%$ & $P$-value \\
\hline \multicolumn{7}{|l|}{ Age (ref: <25 years old) } \\
\hline $25-34$ & 1.51 & $0.91,2.50$ & 0.111 & 1.90 & $1.04,3.46$ & 0.037 \\
\hline $35+$ & 0.77 & $0.45,1.30$ & 0.324 & 1.00 & $0.53,1.89$ & 0.992 \\
\hline \multicolumn{7}{|l|}{ Highest grade completed (ref: no schooling) } \\
\hline 1-3 grade & 1.86 & $1.08,3.21$ & 0.025 & 1.50 & $0.81,2.76$ & 0.198 \\
\hline 4-6 grade & 3.93 & $2.52,6.14$ & $<0.001$ & 2.55 & $1.50,4.33$ & 0.001 \\
\hline Food security (ref: food secure) & 0.89 & $0.61,1.31$ & 0.564 & 0.88 & $0.56,1.38$ & 0.567 \\
\hline Religion ${ }^{a}$ (ref: Hindu) & 0.57 & $0.39,0.83$ & 0.004 & 0.84 & $0.53,1.33$ & 0.466 \\
\hline \multicolumn{7}{|l|}{ Health knowledge ${ }^{b}$ (ref: 0 correct responses) } \\
\hline 1 correct response & 1.42 & $0.91,2.22$ & 0.120 & 1.18 & $0.70,1.99$ & 0.532 \\
\hline 2 correct responses & 3.69 & $2.01,6.74$ & $<0.001$ & 2.66 & $1.29,5.46$ & 0.008 \\
\hline TV/Radio as source of health information ${ }^{c}$ (ref: family \& friends only) & 9.75 & $5.70,16.67$ & $<0.001$ & 7.72 & $4.38,13.60$ & $<0.001$ \\
\hline
\end{tabular}

Model included 526 respondents; pseudo $r^{2}=18.20 \%$.

a Religion: Hindu vs. Muslim.

b Health Knowledge scale composed of 2 questions: "The time during the month when a female loses blood happens because___?" and "If a child has diarrhea, would you give him or her 'more', 'less', 'the same', or 'nothing', to drink?".

c Women were asked to identify sources of health information in addition to family and friends. 
Table 5 Logistic regression model for knowledge of HIV/AIDS (core variables + single independent variables)

\begin{tabular}{|c|c|c|c|c|c|c|}
\hline \multirow[t]{2}{*}{ Independent variables } & \multicolumn{3}{|c|}{ Unadjusted } & \multicolumn{3}{|c|}{ Adjusted for core variables } \\
\hline & OR & $\mathrm{Cl} 95 \%$ & $P$-value & OR & $\mathrm{Cl} 95 \%$ & $P$-value \\
\hline Time in a self-help group (ref: less than one year) & 1.52 & $1.02,2.27$ & 0.041 & 1.58 & $1.03,2.44$ & 0.037 \\
\hline \multicolumn{7}{|l|}{ Savings (ref: 0-219 Rupees) } \\
\hline $220-719$ rupees & 1.54 & $0.84,2.80$ & 0.160 & 1.59 & $0.84,3.00$ & 0.156 \\
\hline 720 - 1439 rupees & 1.84 & $1.02,3.32$ & 0.041 & 1.86 & $1.00,3.48$ & 0.051 \\
\hline$>1440$ rupees & 2.63 & $1.50,4.63$ & 0.001 & 3.43 & $1.85,6.36$ & $<0.001$ \\
\hline \multicolumn{7}{|l|}{ Ideal age for a girl to finish her studies (ref: <age 18) } \\
\hline 18-20 years old & 2.05 & $1.28,3.29$ & 0.003 & 2.01 & $1.23,3.29$ & 0.006 \\
\hline $21+$ years old & 3.61 & $2.04,6.38$ & $<0.001$ & 3.17 & $1.73,5.80$ & $<0.001$ \\
\hline
\end{tabular}

${ }^{a}$ Core variables for the HIV/AIDS model are: Age, Highest Grade Completed, Food Security, and Religion.

educational attainment for mothers in this study was also associated with a belief that girls should obtain more education. This confirms recent findings that emphasize the importance of mothers' education [52], which may also result in better health outcomes for daughters [49]. Given the benefit of even small increases in education, non-formal adult education programs may have a place in improving women's health as suggested by studies of SHGs, NGOs, and microfinance institutions $[17,19,21,25,30]$. Additionally, the current study suggests that efforts to keep girls in school for even a few more years may pay large dividends.

\section{Income and women's empowerment}

The results indicate that women who earned money in the past six months were more likely to report being able to travel alone to seek health care. Similarly, others have shown that in neighboring Bangladesh, income or participation in income-generating activities-typically via microfinance institutions-increase a woman's ability to move outside the home [53-55]. Consistent with our findings is research from Carr et al. that suggests economic empowerment may be a gateway for improving women's empowerment [56]. The influence of SHGs, NGOs, and microfinance institutions on the empowerment of mothers may have long-ranging social impacts, such as increasing the number of years of education and delaying the age of marriage for their daughters. The potential for such effects to improve health outcomes is an area for further research.

\section{Media and health awareness}

In this study, women who reported receiving health information from mass media sources had nearly 8 times higher odds of being knowledgeable about HIV/AIDS, compared to women who received health information through social sources. This finding is not unexpected, especially in a country such as India where, in recent decades, mass media has become an important component of multidimensional approaches to educating individuals about HIV/AIDS [57]. Chatterjee reported that most AIDS-related information obtained by women was acquired through mass media channels [58]. Pallikadavath, Sreedharan and Stones note the value of mass media in educating individuals about HIV/AIDS and suggest that in rural India, radio is most likely to be effective [59]. Similarly, and consistent with the results from our study, research has also shown that mass media

Table 6 Logistic regression model for ability to travel to another village for health services

\begin{tabular}{|c|c|c|c|c|c|c|}
\hline \multirow[t]{2}{*}{ Independent variables } & \multicolumn{3}{|c|}{ Unadjusted } & \multicolumn{3}{|c|}{ Adjusted } \\
\hline & OR & $\mathrm{Cl} 95 \%$ & $P$-value & OR & $\mathrm{Cl} 95 \%$ & $P$-value \\
\hline \multicolumn{7}{|l|}{ Age (ref: <25 years old) } \\
\hline $25-34$ & 1.79 & $1.12,2.85$ & 0.014 & 1.99 & $1.21,3.29$ & 0.007 \\
\hline $35+$ & 1.56 & $0.98,2.46$ & 0.058 & 2.03 & $1.23,3.36$ & 0.006 \\
\hline \multicolumn{7}{|l|}{ Highest grade completed (ref: no schooling) } \\
\hline $1-3$ grade & 1.73 & $1.06,2.85$ & 0.027 & 1.88 & $1.13,3.15$ & 0.016 \\
\hline $4-6$ grade & 1.26 & $0.85,1.87$ & 0.256 & 1.66 & $1.07,2.58$ & 0.024 \\
\hline Food security (ref: food secure) & 1.65 & $1.16,2.35$ & 0.006 & 1.75 & $1.20,2.55$ & 0.003 \\
\hline Earned money in the last 6 months (ref: no) & 2.56 & $1.78,3.70$ & $<0.001$ & 2.52 & $1.73,3.68$ & $<0.001$ \\
\hline
\end{tabular}

Model included 535 respondents; pseudo $r^{2}=6.76 \%$. 
is an important source of information for reproductive health awareness among adolescent girls [60].

The current study's findings provide additional validation of India's investment in mass media reproductive health and HIV/AIDS education. Indeed, the Indian approach may be used as a model of innovation for other developing nations. Within the past decade, the National AIDS Control Organization and the BBC World Service Trust entered into a partnership to produce and disseminate entertainment-education productions through radio and television. The partnership has resulted in widely popular entertainment pieces, which have increased knowledge of HIV/AIDS [57]. Future studies may benefit from investigating the impact on HIV/AIDS information acquired from emerging technologies such as social media. Chatterjee observed that AIDS-related information acquired through mass media may ultimately diffuse into social networks, a process that may be quickened through communication technologies [58].

\section{Limitations}

This study represents a secondary data analysis using available data from a previous study among the same population [31]. Whereas the study was not specifically designed to examine the characteristics of positive deviance among this population, data existed which made possible the current analyses. However, the secondary nature of the data likely limited the ability to test the relative value of many other potentially important factors influencing health outcomes in this population. In addition, the cross-sectional design of the study prevents inference of causal relationships. Further, this study had a sample of women who were $50 \%$ Muslim and 50\% Hindu, which does not reflect the religious distribution of India, where over $80 \%$ are Hindu. However, the Nadia district has a large Muslim minority population that tends to experience more poverty than the Hindu population [61]. Because this is a sample of largely uneducated women in low-income households, it may explain the unique religious distribution in our sample.

Relative to our analysis on a woman's ability to travel alone to another village for health services, the data did not address availability of health services within their own village or whether other reasons for travel to another village, like employment, were the primary motives to travel alone. Both of these questions offer interesting points of exploration in future studies.

\section{Conclusions}

This was an exploratory analysis of factors associated with positive health outcomes among rural women in West Bengal with low levels of formal education. Study findings indicate that women in disadvantaged circumstances can still achieve good outcomes amidst a host of contextual barriers that would predict poor health outcomes. Positive deviants in this context are shown to be women who are able to earn an income, who have access to information through media sources, and who, even though with little schooling, have marginally higher levels of formal education that lead to improved health outcomes. By knowing these characteristics, organizations working in this area can identify women who fit this description and create action plans to encourage more positive deviant behaviors.

Families, and organizations that support these women, need to ensure girls stay in school as long as it is possible each year makes a difference. When girls are already outside of formal education, non-formal education for women can fill in knowledge gaps and social support that will lead to positive outcomes. Further, non-formal education needs to emphasize the importance of education and delayed marriage for daughters, as these beliefs are shown to improve a woman's ability to make better health choices for herself and her family.

Media sources of information matter for improving the lives of rural West Bengali women. Finally, income generating activities for women are important and strategies to increase womens' access to earning their own income greatly improves their chances of healthier outcomes for themselves and their families.

More research is needed to identify how programs aimed at disadvantaged women can capitalize on any amount of formal education during childhood, as well as how women can increase their access to media in resource poor settings, and how women can engage in income generating activities when a majority of their similarly educated peers are unable to do so.

\section{Competing interests}

Our research represents original, unpublished material. It does not overlap nor duplicate other manuscripts that are under review, in press, or published. We have not submitted this manuscript elsewhere for publication. We have no financial or other contractual agreements that might cause conflicts of interest or be perceived as causing conflicts of interest. There are no company products associated with this research; hence, there are no existing financial arrangement between any of the authors and a company.

\section{Authors' contribution}

KNGL, LHG, CAR and BTC oversaw the design of the study. KNGL and LHG analyzed the data. All authors interpreted the data, prepared the manuscript, and approved the final version.

\section{Acknowledgements}

We would like to thank Sri Mayapur Vikas Sangha (SMVS) for allowing us to learn from their clients and their staff members. We also want to express our appreciation to the Nike Foundation for investing in this program and to Sean Kline for his valuable feedback during the writing process. 


\section{Author details}

'Department of Family and Preventive Medicine, University of Utah, Salt Lake City, UT, USA. ²Department of Health Science, Brigham Young University, Provo, UT, USA. ${ }^{3}$ Freedom from Hunger, Davis, CA, USA

Received: 18 May 2012 Accepted: 9 April 2013

Published: 20 April 2013

\section{References}

1. Balk D, Lahiri S: Awareness and knowledge of AIDS among Indian women: evidence from 13 states. Health Transit Rev 1997, 7(Supplement):421-465.

2. Dawn A, Biswas R: Reproductive tract infection: an experience in rural West Bengal. Indian J Public Health 2005, 49(2):102-103.

3. Roy S, Paul B, Biswas B: Awareness regarding communicable diseases among the patients attending general out-patient department of a tertiary care hospital of Kolkata. India. East Afr J Public Health 2009, 6(1):47-50.

4. Tripathi SK, Mandal AK, Dawn G: Profile of oral contraceptive usage by females of the northern part of West Bengal. Indian J Public Health 1992, 36(2):55-56

5. Chacko E: Women's use of contraception in rural India: a village-level study. Health Place 2001, 7(3):197-208

6. Santhya KG, Haberland N, Ram F, Sinha RK, Mohanty SK: Consent and coercion: examining unwanted sex among married young women in India. Int Fam Plan Perspect 2007, 33(3):124-132.

7. Bhattacharyya SK, Basu S, Banerjee S, Dastidar AG, Bagchi SR: An epidemiological survey of carcinoma cervix in north Bengal zone. J Indian Med Assoc 2000, 98(2):60-66.

8. Mittal PC, Srivastava S: Diet, nutritional status and food related traditions of Oraon tribes of New Mal (West Bengal), India. Remote Rural Health 2006, 6(1):385

9. Chakravarty I, Sinha RK: Prevalence of micronutrient deficiency based on results obtained from the national pilot program on control of micronutrient malnutrition. Nutr Rev 2002, 60(5 Pt 2):S53-S58.

10. Bisai $\mathrm{S}$, Bose $\mathrm{K}$ : Undernutrition in the Kora Mudi tribal population, West Bengal, India: a comparison of body mass index and mid-upper-arm circumference. Food Nutr Bull 2009, 30(1):63-67.

11. Bharati P, Shome S, Chakabarty S, Bharati S, Pal M: Burden of anemia and its socioeconomic determinants among adolescent girls in India. Food Nutr Bull 2009, 30(3):217-226.

12. Duclayan $\mathrm{G}$ : Young people in India: their situation and their needs. Population Briefs 2010, 16(2):4-6.

13. Dalal K: Does economic empowerment protect women from intimate partner violence? J Inj Violence Res 2011, 3(1):35-44.

14. Mushtaque A, Chowdhury R, Bhuiya A: Do poverty alleviation programmes reduce inequities in health? The Bangladesh experience. In Poverty, Inequality and Health. An International Perspective. Edited by Leon D, Walt G, Mushtaque A, Chowdhury R, Bhuiya A. Oxford: Oxford University Press, Oxford; 2001.

15. Nanda P: Women's participation in rural credit programmes in Bangladesh and their demand for formal health care: is there a positive impact? Health Econ 1999, 8:415-428.

16. Hamad R, Fernald LC: Microcredit participation and nutrition outcomes among women in Peru. J Epidemiol Community Health 2010. Epub ahead of print.

17. Ahmed SM: Capability development among the ultra-poor in Bangladesh: a case study. J Health Popul Nutr 2009, 27(4):528-535.

18. Leatherman S, Metcalfe M, Geissler K, Dunford C: Integrating microfinance and health strategies: examining the evidence to inform policy and practice. Health Policy Plan 2012, 27(2):85-101.

19. Mohindra K, Haddad S, Narayana D: Can microcredit help improve the health of poor women? Some findings from a cross-sectional study in Kerala, India. Int J Equity Health 2008, 7:2.

20. Bhuiya A, Chowdhury M: Beneficial effects of a woman-focused development programme on child survival: evidence from rural Bangladesh. Soc Sci Med 2002, 55:1553-1560.

21. Van Rompay KK, Madivanan P, Rafiq M, Krupp K, Chakrapani V, Selvam D: Empowering the people: development of an HIV peer education model for low literacy rural communities in India. Hum Resour Health 2008, 18(6):6.
22. Pattenden J: A neoliberalisation of civil society? Self-help groups and the labouring class poor in rural South India. J Peasant Stud 2010, 37:485-512

23. Desai J, Tarozzi A: Microcredit, family planning programs, and contraceptive behavior: evidence from a field experiment in Ethiopia. Demography 2011, 48(2):749-782

24. Marsh DR, Schroder DG: The positive deviance approach to improve health outcomes: Experience and evidence from the field - Preface. Food Nutr Bull 2002, 23(Suppl 4):5-8.

25. Mustaphi P, Dobe M: Positive deviance-the West Bengal experience. Indian J Public Health 2005, 49(4):207-213.

26. Levinson FJ, Barney J, Bassett L, Schultink W: Utilization of positive deviance analysis in evaluating community-based nutrition programs: an application to the Dular program in Bihar, India. Food Nutr Bull 2007, 28(3):259-265

27. Sternin J: Positive deviance: A new paradigm for addressing today's problems today. J Corp Citizenship 2003, 5:57-62.

28. Ahrari M, Kuttab A, Khamis S, Farahat AA, Darmstadt GL, Marsh DR, Levinson FJ: Socioeconomic and behavioral factors associated with successful pregnancy outcomes in upper Egypt: A positive deviance inquiry. Food Nutr Bull 2002, 23(1):83-88.

29. Lapping K, Marsh DR, Rosenbaum J, Swedberg E, Sternin J, Sternin M, Schroeder DG: The positive deviance approach: Challenges and opportunities for the future. Food Nutr Bull 2002, 23(1):128-135.

30. Sethi $V$, Kashyap $S$, Seth $V$ : Effect of nutrition education of mothers on infant feeding practices. Indian J Pediatr 2003, 70(6):463-466.

31. Spielberg F, Crookston BT, Chanani S, Kim J, Kline S, Gray B: Leveraging microfinance networks to scale up HIV and financial education among adolescents and their mothers in West Bengal: a cluster randomized trial and mixed method evaluation. Int J Adolesc Med Health 2013, 17(1):1-10.

32. Rees CA, Long KN, West JH, Gray B, Chanani S, Spielberg F, Crookston BT: Educating for the future: adolescent girls, health, and education in West Bengal, India. Int J Adolesc Med Health 2012, 24(4):321-327.

33. Erulkar A, Muthengi E: Evaluation of Berhane Hewan: a program to delay child marriage in rural Ethiopia. Int Perspect Sex Reprod Health 2009, 35(1):6-14.

34. Subramanian SV, Ozaltin E, Finlay JE: Height of Nations: a socioeconomic analysis of cohort differences and patterns among women in 54 Low-to middle-income countries. PLoS One 2011, 6(4):e18962.

35. Temin M, Levin R: Start with a girl: a new agenda for global health Washington, DC: Center for Global Development; 2009.

36. Raychaudhuri S, Mandal S: Current Status of Knowledge, Attidtude and Practice and Screening for Cervical Cancer in Countries at Different Levels of Development. Asian Pac J Cancer Prev 2012, 13(9):4221-4227.

37. Pandey S, Lin Y: Adjusted Effects of Domestic Violence, Tobacco use, and Indoor Air Pollution from Use of Solid Fuel on Child Mortality. Matern Child Health J 2012. Epub ahead of print.

38. The Millennium Development Goals Report 2010. New York: United Nations; 2010.

39. Yadav SB, Makwana NR, Vadera BN, Dhaduk KM, Gandha KM: Awareness of HIV/AIDS among rural youth in India: a community based cross-sectional study. J Infect Dev Ctrie 2011, 13(10):711-716.

40. Goswami S, Chakraborty S, Mukhopadhyav P: Awareness of HIV/AIDS amongst pregnant women. Indian J Sex Transm Dis 2011, 32(1):62-63.

41. Dasgupta A, Sarkar M: Menstrual hygiene: how hygienic is the adolescent girl? Indian J Community Med 2008, 33(2):77-80.

42. Shanbhag D, Shilpa R, D'Souza N, Josephine P, Singh J, Goud BR: Perceptions regarding menstruation and Practices during menstrual cycles among high school going adolescent girls in resource limited settings around Bangalore city, Karnataka, India. IJCRIMPH 2012, 4(7):1353-1362.

43. Tiwari $\mathrm{H}$, Tiwari $\mathrm{R}$, Oza UN: Knowledge, attitudes and beliefs about menarche of adolescent girls in Anand district, Gujarat. East Mediterr Health J 2006, 12(3-4):428-433.

44. Malhotra A, Schuler SR, Boender C: Measuring women's empowerment as a variable in international development. Washington DC: Gender and Development Group, The World Bank; 2002. Available at: http://siteresources. worldbank.org/INTGENDER/Resources/MalhotraSchulerBoender.pdf.

45. National Family and Health Survey, India 2006. Mumbai (India): Development initiative on supporting healthy adolescents. Washington, DC: International Center for Research on Women; 2004 
46. Melgar-Quinonez HR, Zubieta AC, MkNelly B, Nteziyaremye A, Gerardo MFD, Dunford C: Household food insecurity and food expenditure in Bolivia, Burkina Faso, and the Phillipines. J Nutr 2006, 136:1431S-1437S.

47. Shreiner M: A simple poverty scorecard for India. U.S.A: Report to Grameen Foundation; 2006. http://www.microfinance.com/English/Papers/ Scoring_Poverty_India.pdf.

48. Jensen R, Thornton R: Early Female Marriage in the Developing World In Gender, Development and Marriage. Edited by Caroline S. Oxford: Oxfam GB; 2003

49. Gosh J, Wadhwa V, Kalipeni E: Vulnerability to HIV/AIDS among women of reproductive age in the slums of Delhi and Hyderabad, India. Soc Sci Med 2009, 68:638-642.

50. Govindasamy P, Ramesh BM: Maternal Education and the Utilisation of Maternal and Child Health Services in India. In National Family Health Survey Subject Report, No. 5. Calverton, Maryland: Macro International and Mumbai: International Institute for Population Sciences; 1997.

51. UN Children's Fund (UNICEF): Adolescence, an Age of Opportunity: The State of the World's Children 2011. 2011. http://www.unhcr.org/refworld/docid/ 4d6cfa162.html.

52. Afridi F: Women's empowerment and the goal of parity between the sexes in schooling in India. Pop Stud J Demog 2010, 64(2):131-145.

53. Amin R, Becker S, Bayes A: NGO-promoted microcredit programs and women's empowerment in rural Bangladesh: Quantitative and qualitative evidence. J Developing Areas 1998, 32:221-236.

54. Hashemi SM, Schuler S: The Influence of Women's Changing Roles and Status in Bangladesh's Fertility Transition: Evidence from a Study of Credit Programs and Contraceptive Use. World Devel 1997, 25(4):563-575

55. Hashemi SM, Schuler SR, Riley AP: Rural Credit Programs and Women's Empowerment in Bangladesh. World Devel 1996, 24(4):635-653.

56. Carr M, Chen M, Jabvala R: Speaking Out, Women's Economic Empowerment in South Asia. London: IT Publications; 1996.

57. Sood S, Shefner-Rogers CL, Sengupta M: The impact of a mass media campaign on HIV/AIDS knowledge and behavior change in north India: Results from a longitudinal study. Asian J Commun 2006, 16(3):231-250.

58. Chatterjee N: AIDS-related information exposure in the mass media and discussion within social networks among married women in Bombay, India. AIDS Care 1999, 11(4):443-446.

59. Pallikadavath S, Sreedharan C, Stones RW: Sources of AIDS awareness among women in India. AIDS Care 2006, 18(1):44-48.

60. Singh MM, Devi R, Gupta SS: Awareness and health seeking behaviour of rural adolescent school girls on menstrual and reproductive health problems. Indian J Med Sci 1999, 53:439-443.

61. Minority Concentration District Project: Nadia, West Bengal. Centre for Studies in Social Sciences, Calcutta, Indian Council of Social Science Research. www. icssr.org/Nadia_MCD_Report_Final.pdf.

doi:10.1186/1471-2458-13-372

Cite this article as: Long et al.: Determinants of better health: a crosssectional assessment of positive deviants among women in West Bengal. BMC Public Health 2013 13:372.

\section{Submit your next manuscript to BioMed Central and take full advantage of:}

- Convenient online submission

- Thorough peer review

- No space constraints or color figure charges

- Immediate publication on acceptance

- Inclusion in PubMed, CAS, Scopus and Google Scholar

- Research which is freely available for redistribution 